\title{
Psychological and weight-related characteristics of patients with anorexia nervosa-restricting type who later develop bulimia
} nervosa

\author{
Hiroki Nishimura1, Gen Komaki*1, Tetsuya Ando1, Toshihiro Nakahara², \\ Takakazu Oka ${ }^{3}$, Keisuke Kawai ${ }^{4}$, Toshihiko Nagata ${ }^{5}$, Aya Nishizono6, \\ Yuri Okamoto ${ }^{7}$, Kenjiro Okabe ${ }^{8}$, Masanori Koide ${ }^{9}$, Chikara Yamaguchi ${ }^{10}$, \\ Satoshi Saito11, Kazuyoshi Ohkuma12, Katsutaro Nagata ${ }^{13}$, Tetsuro Naruo ${ }^{14}$, \\ Masato Takii ${ }^{4}$, Nobuo Kiriike ${ }^{5}$, Toshio Ishikawa ${ }^{15}$ and Japanese Genetic \\ Research Group for Eating Disorders ${ }^{1}$
}

Address: ${ }^{1}$ Department of Psychosomatic Research, National Institute of Mental Health, National Center of Neurology and Psychiatry, 4-1-1 Ogawa-Higashi, Kodaira-shi, Tokyo 187-8553, Japan, ${ }^{2}$ Department of Social Science and Medicine, Course for Health Science, Kagoshima University Graduate School of Medical and Dental Science, 8-35-1 Sakuragaoka, Kagoshima-shi, Kagoshima 890-8520, Japan, ${ }^{3}$ Division of Psychosomatic Medicine, Department of Neurology, University of Occupational and Environmental Health, 1-1 Iseigaoka, Yahata-Nishi-ku, Kitakyushu-shi, Fukuoka 807-8555, Japan, ${ }^{4}$ Department of Psychosomatic Medicine, Graduate School of Medical Sciences, Kyushu University, 31-1 Maidashi, Higashi-ku, Fukuoka-shi, Fukuoka 812-8582, Japan, ${ }^{5}$ Department of Neuropsychiatry, Graduate School of Medicine, Osaka City University, 1-4-3 Asahimachi, Abeno-ku, Osaka-shi, Osaka 545-8585, Japan, ${ }^{6}$ Tokyo Institute of Psychiatry, 2-1-8 Kamikitazawa, Setagaya-ku, Tokyo 156-8585, Japan, ${ }^{7}$ Health Service Center, Hiroshima University, 1-7-1 Kagamiyama, Higashihiroshima-shi, Hiroshima 739-8521, Japan, ${ }^{8}$ Department of Psychosomatic Medicine, Tenri Hospital, 200 Mishima-cho, Tenri-shi, Nara 632-8552, Japan, ${ }^{9}$ Department of Internal Medicine, Hoshigaoka Maternity Hospital, 27 Inoue-cho, Chikusa-ku, Nagoya-shi, Aichi 464-0026, Japan, ${ }^{10}$ Division of General Medicine and Neuropsychiatry, Aichi Medical University Hospital, Nagakute, Aichi 480-1195, Japan, ${ }^{11}$ Department of Neuropsychiatry, School of Medicine, Sapporo Medical University, S-1, W-16, Chuo-ku, Sapporo-shi, Hokkaido 060-8543, Japan, ${ }^{12}$ Department of Internal Medicine, Yufuin Kohseinenkin Hospital, 252 Kawaminami, Ufuin-cho, Ufu-shi, Oita, 879-5193, Japan, ${ }^{13}$ Department of Psychosomatic Medicine, Hamamatsu University School of Medicine, 1-20-1 Handayam, Hamamatsu-shi, Shizuoka 431-3192, Japan, ${ }^{14}$ Department of Psychosomatic Medicine, Nogami Hospital, 1-4-1 Komatsubara, Kagoshima-shi, Kagoshima 891-0114, Japan and ${ }^{15}$ Department of Psychosomatic Medicine, Kohnodai Hospital, National Center of Neurology and Psychiatry, 1-7-1 Kohnodai, Ichikawa-shi, Chiba 272-8516, Japan

Email: Hiroki Nishimura - nisimura@ncnp.go.jp; Gen Komaki* - komaki@ncnp.go.jp; Tetsuya Ando - ando-t@ncnp.go.jp; Toshihiro Nakahara - ayana-n@m3.kufm.kagoshima-u.ac.jp; Takakazu Oka - toka@med.uoeh-u.ac.jp; Keisuke Kawai - kawai@cephal.med.kyushu-u.ac.jp; Toshihiko Nagata - toshnn@ hotmail.com; Aya Nishizono - nisizono@prit.go.jp; Yuri Okamoto - yurioka@hiroshima-u.ac.jp; Kenjiro Okabe - okabek@sky.plala.or.jp; Masanori Koide - psm-k@toukeikai.com; Chikara Yamaguchi - chikara@aichi-med-u.ac.jp; Satoshi Saito - saitos@sapmed.ac.jp; Kazuyoshi Ohkuma - ookumak@nifty.com; Katsutaro Nagata - hacap2@hama-med.ac.jp; Tetsuro Naruo - tnaruo33@yahoo.co.jp; Masato Takii - takii@cephal.med.kyushu-u.ac.jp; Nobuo Kiriike - kiri@med.osaka-cu.ac.jp; Toshio Ishikawa - ishikawa@ncnpk2.hosp.go.jp; Japanese Genetic Research Group for Eating Disorders - komaki@ncnp.go.jp

* Corresponding author

Published: 12 February 2008

BioPsychoSocial Medicine 2008, 2:5 doi:10.1186/175I-0759-2-5

This article is available from: http://www.bpsmedicine.com/content/2/l/5

(c) 2008 Nishimura et al; licensee BioMed Central Ltd.

This is an Open Access article distributed under the terms of the Creative Commons Attribution License (http://creativecommons.org/licenses/by/2.0), which permits unrestricted use, distribution, and reproduction in any medium, provided the original work is properly cited.

Received: 26 September 2007

Accepted: 12 February 2008

\begin{abstract}
Background: Patients with anorexia nervosa-restricting type (AN-R) sometimes develop accompanying bulimic symptoms or the full syndrome of bulimia nervosa (BN). If clinicians could predict who might change into the bulimic sub-type or $\mathrm{BN}$, preventative steps could be taken. Therefore, we investigated anthropometric and psychological factors possibly associated with such changes.
\end{abstract}


Method: All participants were from a study by the Japanese Genetic Research Group for Eating Disorders. Of 80 patients initially diagnosed with AN-R, 22 changed to the AN-Binge Eating/Purging Type (AN-BP) and 14 to BN for some period of time. The remaining 44 patients remained AN-R only from the onset to the investigation period. Variables compared by ANOVA included anthropometric measures, personality traits such as Multiple Perfectionism Scale scores and Temperament and Character Inventory scores, and Beck Depression Inventory-II scores.

Results: In comparison with AN-R only patients, those who developed BN had significantly higher current BMI $(p<0.05)$ and maximum BMI in the past $(p<0.05)$. They also scored significantly higher for the psychological characteristic of parental criticism $(p<0.05)$ and lower in selfdirectedness $(p<0.05)$, which confirms previous reports, but these differences disappeared when the depression score was used as a co-variant. No significant differences were obtained for personality traits or depression among the AN-R only patients irrespective of their duration of illness.

Conclusion: The present findings suggest a tendency toward obesity among patients who cross over from AN-R to BN. Low self-directedness and high parental criticism may be associated with the development of $\mathrm{BN}$ by patients with $\mathrm{AN}-\mathrm{R}$, although the differences may also be associated with depression.

\section{Background}

Many eating disordered patients migrate between diagnostic categories, particularly from the initial diagnosis $[1,2]$. A diagnostic crossover from Anorexia Nervosa (AN) to Bulimia Nervosa (BN) is one of the most commonly observed [2,3]. Particularly for patients with initial diagnoses of AN restricting-type (AN-R), treatment is said to be difficult because many develop binging and vomiting. Previous studies of patients with an initial diagnosis of AN-R have reported that $62 \%$ changed to the AN bingeeating/purging type (AN-BP) [4] and 21 36\% changed to BN $[5,6]$. These crossovers usually occurred within the first five years after onset of the eating disorder. Fichter et al. [7] found that patients crossed over from AN-R to AN$\mathrm{BP}$ at a rate of $16.7 \%$ after two years, $10.3 \%$ after six years, and $3.7 \%$ after 12 years, and that patients crossed over from AN-R to BN at a rate of $13.3 \%$ after two years and $3.4 \%$ after six years.

These lines of evidence suggest that predicting the possibility of diagnostic crossover from AN-R at an early stage would be useful in treatment, because bulimia and purging behavior predict an unfavorable prognosis $[8,9]$ and an increase in time to remission [5]. Only a few studies have examined the psychological factors possibly related to such crossovers from AN-R. Tozzi et al. [6] found that higher levels of 'Parental criticism' (a subscale of the Multidimensional Perfectionism Scale [MPS] for measuring perfectionism) and lower levels of 'Self-directedness' (a subscale of the Temperament and Character Inventory [TCI] for measuring personality) predicted crossover from AN-R to BN.
However, a relationship between these factors and depression has been documented $[10,11]$. Depression is generally prevalent among women with eating disorders $[12,13]$. Furthermore, several studies have suggested that patients with AN-BP are more depressive than those with AN-R $[12,13]$, and that patients with BN are more depressive than those with AN [14]. Thus, it is possible that the degree of depression may be a major psychological factor related to the crossover from AN-R to $\mathrm{BN}$. Indeed, the necessity of considering state variables such as depression in examinations of personality traits has been shown $[10,15]$.

In addition, regarding the factors of body mass index (BMI) and obesity, patients with $\mathrm{BN}$ were higher than patients with AN-R on maximum BMI in the past $[16,17]$ and childhood obesity is a reported risk factor for BN [1]. The relationship of a tendency to gain weight easily and the crossover from AN-R should be investigated.

Therefore, the aim of this study was to examine psychological factors and the tendency toward obesity related to the crossover from AN-R, and to examine the relationship between these psychological factors and depression.

\section{Method \\ Participants}

Patient data were collected from the institutions that participated in a study by the Japanese Genetic Research Group for Eating Disorders [18] (see Additional File 1). Participants were required to meet the following criteria: (1) agreement of participation/cooperation in the genetic analysis study after informed consent by the chief physician and agreement by the parents when a subject was 
under 20 years old, (2) diagnosis of an eating disorder based on the Diagnostic and Statistical Manual of Mental Disorders, Fourth Edition (DSM-IV), (3) duration of illness of the eating disorder of more than three months, (4) no current diagnosis of mental retardation (IQ $<70)$, organic brain disease, evident psychotic disorder (Schizophrenia, Bipolar Disorder) or somatic diseases that affect body weight, appetite, or eating. After applying these criteria, 373 patients were recruited [18]. From these patients, 25 for whom the details of the course of illness were unknown and 115 patients whose initial diagnosis was not AN-R were excluded. Of the remaining 233 patients, 153 were further excluded: (1) patients who crossed over to eating disorders not otherwise specified $(n=16),(2)$ patients who did not agree to fill out the questionnaires (n $=89$ ) and those who did not complete all of the data-sets of the questionnaires ( $\mathrm{n}=38)$, (3) patients who had completely recovered at the time of the investigation $(n=10$; 5 with AN-R only, 1 who crossed over from AN-R to AN$\mathrm{BP}$, and 4 who crossed over from AN-R to BN).

Thus, 80 patients who were all undergoing treatment for their illness at the time of the investigation ( 1 man and 79 women) were participants in the study. Their basic demographic variables (age at onset, age at investigation, duration of illness, current BMI, maximum BMI in the past, and minimum BMI in the past) were obtained for analysis. At the time of the investigation, their mean age was $24.00 \pm 7.43$ years old, duration of illness was $58.89 \pm$ 53.14 months, and current BMI was $15.27 \pm 3.05 \mathrm{~kg} / \mathrm{m}^{2}$. There were no significant differences from those who were excluded from the current study (mean age, $22.13 \pm 7.42$ years old; duration of illness, $59.17 \pm 64.24$ months), except for current BMI $\left(16.49 \pm 3.63 \mathrm{~kg} / \mathrm{m}^{2}\right)$.

In accordance with the course of illness from the onset to the investigation period, the patients were classified into three groups: patients with AN-R only $(\mathrm{n}=44)$, patients who crossed over from AN-R to AN-BP $(n=22)$, and patients who crossed over from AN-R to $\mathrm{BN}(\mathrm{n}=14)$. Patients who crossed over from AN-R to AN-BP included patients who returned to AN-R again after having developed AN-BP ( $\mathrm{n}=4$; duration of AN-BP was 12-102 months). Patients who crossed over from AN-R to BN included patients who developed $\mathrm{BN}$ via $\mathrm{AN}-\mathrm{BP}$ or who returned to AN-R again after having developed $\mathrm{BN}(\mathrm{n}=1$; duration of $\mathrm{BN}$ was 7 months).

The current study was approved by the local ethics committees of the participating institutions and the National Center of Neurology and Psychiatry. Written informed consent was obtained after a full explanation of the study at each institution.

\section{Procedure}

Informed consent was obtained from each participant. Clinical information such as 'age at onset', 'age at investigation', 'duration of illness', 'current BMI', 'maximum and minimum BMI in the past', and 'diagnostic crossover' was collected from the clinical records. The participants completed the following questionnaires at their treatment facility.

\section{Multidimensional Perfectionism Scale (MPS)}

The MPS [19] was used to evaluate multidimensional facets of perfectionism. The MPS is a 35-item questionnaire that measures six dimensions of perfectionism (Concern over mistakes, Personal standards, Parental expectations, Parental criticism, Doubt about actions, and Organization). Each item is scored on a five point scale ranging from 1 (strongly disagree) to 5 (strongly agree). A higher score indicates greater perfectionism. The MPS has demonstrated adequate reliability and high concurrent validity [19] and the Japanese version of MPS has also been validated [20].

Temperament and Character Inventory- I 25-4 (TCl)

The TCI is a 125-item inventory that consists of seven independent dimensions (Novelty seeking, Harm avoidance, Reward dependence, Persistence, Self-directedness, and Cooperativeness) that is based on a psychobiological model of personality [21]. Each item is scored on a four point scale ranging from 1 (disagree) to 4 (agree). The reliability and validity of the Japanese version of the TCI are well documented [22].

\section{Beck Depression Inventory-II (BDI-II)}

The BDI-II is a 21-item self-report questionnaire used to assess the severity of depression symptoms, based on the diagnostic criteria for depressive disorders in DSM-IV. Each item is scored from 0 to 3 , with a higher score indicating greater intensity of the symptom. The total score is the sum of the items, ranging from 0 to 63; a higher score indicates greater depression. The reliability and validity of the Japanese version of the BDI-II are well documented [23].

\section{Statistical analyses}

Data analysis was done with SPSS $11.0 \mathrm{~J}$ for Windows. Comparisons of more than three groups were performed with a one-way analysis of variance (ANOVA), and post hoc comparisons were performed with Dunnett's test or the Bonferroni test. To examine the effect of depression, one-way analyses of covariance (ANCOVA) were performed with the BDI-II scores entered as a covariate. 


\section{Results}

\section{Patient characteristics}

Table 1 shows the clinical information, demographic data, and BDI-II scores of the three groups. The results of the ANOVA revealed significant differences among the three groups in duration of illness $(\mathrm{p}<0.01)$, current BMI $(\mathrm{p}<0.01)$, maximum BMI in the past $(\mathrm{p}<0.05)$, and BDIII score $(\mathrm{p}<0.05)$. Post hoc comparisons using Dunnett's test with patients with AN-R only showed that the patients who crossed over from AN-R to AN-BP had significantly longer durations of illness than those with AN-R only ( $\mathrm{p}$ $<0.05)$. Patients who crossed over from AN-R to BN had significantly higher current BMI ( $\mathrm{p}<0.05)$, maximum BMI in the past $(\mathrm{p}<0.05)$, and BDI-II scores $(\mathrm{p}<0.05)$ than those with AN-R only.

\section{Comparisons of the MPS and TCl scores of the three groups}

Table 2 shows the MPS and TCI scores of the three groups. The results of the ANOVA showed 'Parental criticism' on the MPS to be approaching significance $(\mathrm{p}<0.10)$ and 'Self-directedness' on the TCI to be significant $(\mathrm{p}<0.05)$. Post hoc comparisons using Dunnett's test with patients with AN-R only showed that patients who crossed over from AN-R to BN had significantly higher 'Parental criticism' scores $(\mathrm{p}<0.05)$ and lower 'Self-directedness' scores $(\mathrm{p}<0.05)$ than patients with AN-R only.

These significant effects, however, disappeared in the ANCOVA in which BDI-II scores were entered as a covariate ('Parental criticism', $\mathrm{F}(2,80)=1.69$, $\mathrm{p}=0.19$; 'Selfdirectedness', $\mathrm{F}(2,80)=0.95, \mathrm{p}=0.39)$.

\section{Examination of patients with AN-R only}

To examine the effect of psychological factors related to the 'Duration of illness' of patients with AN-R only, we divided these patients into four categories based on the duration of illness: I, less than 1 year $(\mathrm{n}=11)$; II, $1 \sim 2$ years $(\mathrm{n}=13)$; III, 3 5 years $(\mathrm{n}=8)$; IV, more than 5 years $(\mathrm{n}=$ 12). Table 3 shows the BDI-II, MPS, and TCI scores of the four categories. The results of the ANOVA revealed a significant effect only for the MPS subscale 'Parental expectations' ( $\mathrm{p}<0.05)$. Post hoc comparisons using the Bonferroni test, however, showed that the four groups were not significantly different.

\section{Discussion}

In comparison with patients with persistent AN-R, those who developed $\mathrm{BN}$ were significantly higher in both current BMI and maximum BMI in the past. They also scored significantly higher in 'Parental criticism' and lower in 'Self-directedness', but both these trait factors disappeared when depression scores were used as a co-variant. No significant differences were observed for any of the personality traits surveyed among patients with persistent AN-R irrespective of their duration of illness.

A tendency toward obesity among patients who cross over from $\mathrm{AN}-\mathrm{R}$ to $\mathrm{BN}$ is reported by previous studies $[16,17]$. Because childhood obesity is a predisposition of $\mathrm{BN}$ [1], the present results suggest that patients with AN-R at onset who were overweight in the past are inclined to gain weight and will develop $\mathrm{BN}$ over the course of their illness. This finding is compatible with recent genetic studies [24]. The chromosomal region $10 \mathrm{p}$, a susceptibility

Table I: Clinical information, demographic data, and BDI-II scores

\begin{tabular}{|c|c|c|c|c|c|c|c|c|c|c|}
\hline & \multicolumn{3}{|c|}{ Patients with AN-R only } & \multicolumn{3}{|c|}{$\begin{array}{l}\text { Patients who crossed over from AN-R to } \\
\text { AN-BP }\end{array}$} & \multicolumn{3}{|c|}{$\begin{array}{l}\text { Patients who crossed over from AN-R to } \\
\text { BN }\end{array}$} & \multirow[b]{2}{*}{$F$ values } \\
\hline & Mean & $(\mathrm{SD})$ & $\mathrm{n}$ & Mean & $(\mathrm{SD})$ & $\mathrm{n}$ & Mean & (SD) & $\mathrm{n}$ & \\
\hline $\begin{array}{l}\text { Age at onset } \\
\text { (yrs.) }\end{array}$ & 18.66 & $(6.22)$ & 42 & 19.60 & $(4.28)$ & 22 & 17.55 & $(2.91)$ & 13 & 0.62 \\
\hline Age (yrs.) & 22.72 & $(8.10)$ & 43 & 26.64 & $(7.05)$ & 22 & 23.79 & $(4.66)$ & 14 & 2.09 \\
\hline $\begin{array}{l}\text { Duration of } \\
\text { illness (mo) }\end{array}$ & 42.55 & $(45.26)$ & 44 & $84.45^{a}$ & (63.33) & 22 & 70.92 & $(40.70)$ & 13 & $5.54 * *$ \\
\hline $\begin{array}{l}\text { Current BMI } \\
\left(\mathrm{kg} / \mathrm{m}^{2}\right)\end{array}$ & 14.36 & $(2.14)$ & 41 & 14.38 & $(1.32)$ & 22 & $19.35^{a}$ & $(3.96)$ & 14 & $24.96 * *$ \\
\hline $\begin{array}{l}\text { Maximum BMI } \\
\left(\mathrm{kg} / \mathrm{m}^{2}\right)\end{array}$ & 19.97 & $(2.59)$ & 42 & 20.83 & $(3.63)$ & 20 & $22.73^{a}$ & $(2.92)$ & 14 & $4.62 *$ \\
\hline $\begin{array}{l}\text { Minimum BMI } \\
\left(\mathrm{kg} / \mathrm{m}^{2}\right)\end{array}$ & 12.36 & $(1.96)$ & 42 & 12.24 & $(1.68)$ & 20 & 13.64 & $(1.93)$ & 14 & 2.83 \\
\hline $\begin{array}{l}\text { Differences of } \\
\mathrm{BMI}\left(\mathrm{kg} / \mathrm{m}^{2}\right)\end{array}$ & 7.61 & $(2.80)$ & 42 & 8.60 & $(3.34)$ & 20 & 9.09 & $(3.00)$ & 14 & 1.61 \\
\hline BDI-II & 18.75 & $(13.28)$ & 44 & 22.36 & (II.82) & 22 & $29.36^{a}$ & $(12.22)$ & 14 & $3.75^{*}$ \\
\hline
\end{tabular}

Statistical significance by ANOVA: $*_{p}<.05, * * p<.01$

a Superscript represents significant differences of $p<.05$ compared with patients with AN-R only by the Dunnett's test.

AN-R = Anorexia Nervosa Restricting-type, AN-BP = Anorexia Nervosa Binge-eating/purging type, BN = Bulimia Nervosa, BMI = Body Mass Index,

BDI-II = Beck Depression Inventory-II, SD = standard deviation 
Table 2: Comparisons of the dimensions of the Multidimensional Perfectionism Scale and the Temperament and Character Inventory

\begin{tabular}{|c|c|c|c|c|c|c|c|}
\hline & \multirow{2}{*}{\multicolumn{2}{|c|}{$\begin{array}{c}\text { Patients with AN-R only } \\
n=44\end{array}$}} & \multirow{2}{*}{\multicolumn{2}{|c|}{$\begin{array}{l}\text { Patients who crossed over from AN-R to } \\
\text { AN-BP } \\
n=22\end{array}$}} & \multirow{2}{*}{\multicolumn{2}{|c|}{$\begin{array}{l}\text { Patients who crossed over from AN-R to } \\
\text { BN } \\
\qquad n=14\end{array}$}} & \multirow[b]{3}{*}{$F$ values } \\
\hline & & & & & & & \\
\hline & Mean & (SD) & Mean & (SD) & Mean & (SD) & \\
\hline \multicolumn{8}{|l|}{ MPS } \\
\hline $\begin{array}{l}\text { Concern over } \\
\text { mistakes }\end{array}$ & 28.11 & $(6.99)$ & 27.41 & $(10.27)$ & 30.21 & $(7.06)$ & 0.55 \\
\hline $\begin{array}{l}\text { Personal } \\
\text { standards }\end{array}$ & 20.80 & $(5.18)$ & 21.68 & $(6.25)$ & 24.14 & $(5.95)$ & 1.88 \\
\hline $\begin{array}{l}\text { Parental } \\
\text { expectations }\end{array}$ & 11.11 & $(5.10)$ & 12.55 & $(4.7 I)$ & 14.14 & $(5.27)$ & 2.08 \\
\hline Parental criticism & 9.07 & (3.86) & 9.23 & $(3.12)$ & $11.57^{a}$ & $(3.08)$ & $2.77^{\dagger}$ \\
\hline $\begin{array}{l}\text { Doubts about } \\
\text { actions }\end{array}$ & 12.89 & $(3.64)$ & 12.18 & $(3.38)$ & 12.50 & $(2.85)$ & 0.32 \\
\hline Organization & 20.20 & (3.86) & 21.09 & $(4.16)$ & 19.93 & $(3.25)$ & 0.52 \\
\hline \multicolumn{8}{|l|}{$\mathrm{TCl}$} \\
\hline Novelty seeking & 45.55 & $(6.42)$ & 45.55 & $(6.21)$ & 49.00 & $(5.94)$ & 1.75 \\
\hline Harm avoidance & 60.70 & $(9.67)$ & 60.73 & (7.75) & 64.79 & (7.47) & 1.23 \\
\hline $\begin{array}{l}\text { Reward } \\
\text { dependence }\end{array}$ & 42.39 & $(5.33)$ & 42.23 & (4.99) & 40.64 & $(5.67)$ & 0.60 \\
\hline Persistence & $|3.6|$ & $(3.10)$ & 15.23 & $(3.54)$ & 14.29 & $(2.92)$ & 1.88 \\
\hline Self-directedness & 61.89 & (II.I7) & 57.82 & $(10.33)$ & $53.79 a$ & $(6.57)$ & $3.62 *$ \\
\hline Cooperativeness & 73.84 & $(8.03)$ & 76.95 & $(6.7 I)$ & 72.00 & $(9.96)$ & 1.83 \\
\hline $\begin{array}{l}\text { Self- } \\
\text { transcendence }\end{array}$ & 26.36 & $(7.31)$ & 26.27 & $(8.31)$ & 28.21 & $(5.03)$ & 0.39 \\
\hline
\end{tabular}

Statistical significance by ANOVA: $\dagger_{p}<.10,{ }^{*} p<.05$

aSuperscript represents significant differences of $p<.05$ compared with patients with AN-R only by the Dunnett's test.

AN-R = Anorexia Nervosa Restricting-type, AN-BP = Anorexia Nervosa Binge-eating/purging type, BN = Bulimia Nervosa, MPS = Multidimensional

Perfectionism Scale, $\mathrm{TCl}=$ Temperament and Character Inventory, $\mathrm{SD}=$ standard deviation

factor for BN, has been implicated in obesity [24] and the preproghrelin gene single nucleotide polymorphisms, another susceptibility factor for BN [18], were associated with higher current and maximum BMI in the past among female students $[18,25]$. In addition, the above genetic polymorphisms were related to higher 'Drive for Thinness-Body Dissatisfaction' scores measured by the Eating Disorder Inventory (EDI) [18,25].

Consistent with previous findings [6], high 'Parental criticism' and low 'Self-directedness' were associated with crossover from AN-R to BN in Japanese patients, indicating no ethnic or cultural effects on the psychological factors related to crossover from AN-R to BN. The finding of higher 'Parental criticism' scores of patients who crossed over from AN-R to BN is consistent with previous findings: lack of expressed empathy/affection from the parents predicted binge eating in AN-R patients [5]; stronger perception of deficits in parental nurturance in $\mathrm{BN}$ patients than in AN patients [26]; and 'Parental criticism' scores predicting bulimia scores measured by the EDI during a stressful situation for normal female high school students
[27]. Families in which members are criticized may be weak in support for their members undergoing treatment, substantially inhibiting the treatment process and inclining restrictors to begin binging and vomiting. Moreover, maternal critical comments [28] and lack of parental care [29] are associated with poor outcomes in eating disorder patients. Thus, this study further suggests the importance of a supportive family system for the disease course of eating disordered patients.

The basic concept of 'Self-directedness' is "self-determination and 'willpower' or the ability of an individual to control, regulate, and adapt their behavior to fit the situation in accord with individually chosen goals and values"[21]. Patients with eating disorders who manifest low 'Selfdirectedness' are not capable of continuing the restriction behaviors that help them get thinner. Accordingly, these patients may begin binging and/or vomiting, which requires a change in diagnosis. Actually, 'Self-directedness' scores were lower in BN than AN-R $[16,17,30]$. Moreover, low 'Self-directedness' is associated with poorer outcome in AN patients [29,31]. Based on these lines of 
Table 3: Comparisons of the effect of duration of illness of patients with AN-R only on dimensions of the Multidimensional Perfectionism Scale, the Temperament and Character Inventory and the Beck Depression Inventory-II

\begin{tabular}{|c|c|c|c|c|c|c|c|c|c|}
\hline \multirow[t]{3}{*}{ Duration of illness } & \multirow{2}{*}{\multicolumn{2}{|c|}{$\begin{array}{l}\text { Less than I year } \\
\qquad n=11\end{array}$}} & \multirow{2}{*}{\multicolumn{2}{|c|}{$\begin{array}{c}\mathrm{I}-2 \text { years } \\
n=13\end{array}$}} & \multirow{2}{*}{\multicolumn{2}{|c|}{$\begin{array}{c}3-5 \text { years } \\
n=8\end{array}$}} & \multirow{2}{*}{\multicolumn{2}{|c|}{$\begin{array}{c}\text { More than } 5 \text { years } \\
n=12\end{array}$}} & \multirow[b]{3}{*}{$F$ values } \\
\hline & & & & & & & & & \\
\hline & Mean & (SD) & Mean & $(\mathrm{SD})$ & Mean & $(S D)$ & Mean & $(S D)$ & \\
\hline \multicolumn{10}{|l|}{ MPS } \\
\hline Concern over mistakes & 26.55 & $(4.18)$ & 31.85 & $(7.39)$ & 28.75 & $(8.43)$ & 25.08 & $(6.40)$ & 2.41 \\
\hline Personal standards & 21.64 & $(6.47)$ & 22.00 & (3.79) & 19.00 & $(6.50)$ & 19.92 & $(4.34)$ & 0.75 \\
\hline Parental expectations & 8.55 & (3.64) & 13.15 & $(5.24)$ & 8.25 & $(3.28)$ & 13.17 & $(5.56)$ & $3.69 *$ \\
\hline Parental criticism & 8.18 & (3.84) & 9.62 & $(3.73)$ & 8.38 & $(3.34)$ & 9.75 & $(4.54)$ & 0.47 \\
\hline Doubts about actions & 14.27 & $(2.20)$ & 12.69 & $(4.05)$ & 12.88 & $(4.22)$ & 11.83 & $(3.86)$ & 0.87 \\
\hline Organization & 20.73 & $(2.72)$ & 20.62 & $(4.52)$ & 19.75 & $(4.59)$ & 19.58 & $(3.85)$ & 0.24 \\
\hline \multicolumn{10}{|l|}{$\mathrm{TCl}$} \\
\hline Novelty seeking & 45.73 & $(7.27)$ & 47.92 & $(5.79)$ & 43.50 & $(7.65)$ & 44.17 & $(5.22)$ & 1.06 \\
\hline Harm avoidance & 61.18 & $(10.23)$ & 61.46 & $(8.52)$ & 60.50 & $(8.80)$ & 59.58 & (II.83) & 0.09 \\
\hline Reward dependence & 41.09 & $(4.72)$ & 41.00 & $(6.30)$ & 46.00 & $(4.78)$ & 42.67 & $(4.40)$ & 1.85 \\
\hline Persistence & 14.27 & $(3.13)$ & 12.38 & $(2.40)$ & 14.13 & $(4.64)$ & 14.00 & $(2.45)$ & 0.98 \\
\hline Self-directedness & 61.45 & $(10.69)$ & 56.54 & (II.23) & 65.88 & $(6.08)$ & 65.42 & (12.77) & 1.84 \\
\hline Cooperativeness & 74.91 & $(5.47)$ & 69.31 & $(10.61)$ & 77.25 & $(5.26)$ & 75.50 & $(6.92)$ & 2.28 \\
\hline Self-transcendence & 31.09 & $(9.02)$ & 24.15 & $(4.22)$ & 25.13 & $(8.64)$ & 25.25 & $(6.11)$ & 2.30 \\
\hline BDI-II & 19.27 & (13.87) & 21.46 & (16.88) & 18.25 & (13.30) & 15.67 & $(8.46)$ & 0.39 \\
\hline
\end{tabular}

Statistical significance: ${ }^{*} p<.05$

MPS = Multidimensional Perfectionism Scale, TCI = Temperament and Character Inventory, BDI-II = Beck Depression Inventory-II, SD = standard deviation

evidence, our findings suggest the importance of paying careful attention to 'Self-directedness' in the treatment process of AN-R patients.

We also observed the possibility that crossover from AN$\mathrm{R}$ to $\mathrm{BN}$ is related to depression. While depression predicts future increases of binge eating in normal females [32-34] and in eating disorder patients [35], Tenconi et al. [36] reported that the degree of depression at baseline of patients with an initial diagnosis of AN-R did not predict the onset of binge eating. It is possible that depression may occur during the crossover period and that the depression may be caused by binging and vomiting. This hypothesis is supported by a study showing that the symptoms of eating-related concerns prospectively predict the onset of depression in adolescent girls [37]. In our study, relationships between depression and 'Parental criticism' and 'Self-directedness' were suggested. It is possible that trait factors such as 'Parental criticism' and 'Self-directedness' create a susceptibility to the development of depression, as low 'Self-directedness' was found to predict depression in normal undergraduates [38]. Otherwise, it is possible that the self-evaluation of trait factors was biased by a depressive mood $[15,39]$. The design of the present study, however, does not allow for an absolute determination of causation. Longitudinal investigation is necessary to confirm the relationship between crossover and the depression of patients with an initial diagnosis of AN-R.
In contrast to the findings for the patients who developed $\mathrm{BN}$, patients who crossed over from AN-R to AN-BP showed no differences in psychological factors from those with AN-R only. This finding is supported by a cross-sectional study comparing the MPS scores of AN-BP and AN$R$ patients, where no significant differences were observed [40]. Regarding the TCI scores, however, the findings in different studies are not consistent: no significant differences between AN-R and AN-BP $[13,16]$; higher 'Novelty seeking' in AN-BP than AN-R [30,41,42]; and higher 'Selfdirectedness' in AN-R than AN-BP $[41,42]$. Because 'Novelty seeking' and 'Self-directedness' are reported to be associated with personality disorders $[43,44]$ and alcohol abuse [45], it is possible that the co-morbidity of Axis I and II disorders merely contributes to those differences $[30,41,42]$. In addition, both of these AN sub-type groups were different in 'duration of illness'; this should be considered as a possible confounding factor, although there were not adequate numbers of subjects for a proper comparison. Further studies are needed regarding psychiatric co-morbidities and duration of illness among AN-R patients who develop AN-BP.

Scores on personality measures are also reported to be influenced by the degree of recovery from eating disorders $[29,46]$. In the present study, only those patients in an active state of illness were investigated. Although personality assessment and function might be influenced by the symptoms themselves (e.g., starvation) in an actively ill 
state [47], it is generally reported that personality is rather consistent $[48,49]$, and temperament and character are independent of body weight in AN [41]. However, the number of patients excluded from our study because of their recovery at the time of the investigations was rather small; five with AN-R only, one who crossed over from AN-R to AN-BP, and four who crossed over from AN-R to $\mathrm{BN}$. It is impossible to precisely compare the influence of symptoms of those in an active state of illness and those who have recovered.

Based on the recent findings that the highest rate of crossover was observed within the first five years after the onset of AN-R [5,6], we compared the patients who crossed over five years or more after the onset $(n=4)$ and those who crossed over within five years $(n=32)$. There were no significant associations of any of the psychological characteristics with the duration of illness and no significant differences on the MPS, TCI, or BDI-II between the two groups (data are not shown). Therefore, the influence of duration of AN-R is rather small on the psychological characteristics of these patients in the current study.

Finally, the present findings have clinical implications for the treatment of patients with eating disorders. Investigating the tendency toward obesity or a depressive state in a clinical setting will help us to predict crossover from AN$\mathrm{R}$ to BN. Examining patient characteristics such as 'Parental criticism' and 'Self-directedness' may predict not only crossover but also, at least in part, the outcome of treatment. Cognitive and behavioral treatment, as well as nutritional interventions, for such risk factors will be necessary.

\section{Conclusion}

The current results present the demographic and psychological characteristics of patients who cross over from AN$\mathrm{R}$ to $\mathrm{BN}$ : a tendency toward obesity and the psychological characteristics of low self-directedness and high parental criticism. However, these psychological traits may also be associated with depression. Further research is needed to clarify the causal role of depression and its relationship to the identified psychological characteristics of patients who cross over.

\section{Competing interests}

The author(s) declare that they have no competing interests.

\section{Authors' contributions}

HN performed the statistical analysis and drafted the manuscript. GK conceived the study design, collected the clinical data set, and drafted the manuscript. TA participated in the design of the study and collected the clinical data set. TNakahara, TO, KK, T. Nagata, AN, YO, KOkabe,
MK, CY, SS, KOhkuma, KN, TNaruo, MT, NK, TI and the Japanese Genetic Research Group for Eating Disorders collected the clinical data set. All authors read and approved the final manuscript.

\section{Additional material}

\section{Additional file 1}

Japanese Genetic Research Group for Eating Disorders. The investigators in this multi-site study group.

Click here for file

[http://www.biomedcentral.com/content/supplementary/1751-

0759-2-5-S1.xls]

\section{Acknowledgements}

This study was supported by Grants-in-Aid for Scientific Research I 40 I 3062 (to GK) from the Ministry of Education, Culture, Sports, Science and Technology, and by a Research Grant from the Japan New Energy and Industrial Technology Development Organization (NEDO) and the Ministry of Economy, Trade and Industry (METI) (to GK).

\section{References}

I. Fairburn CG, Harrison PJ: Eating disorders. Lancet 2003, 36 I (9355):407-4I6.

2. Milos G, Spindler A, Schnyder U, Fairburn CG: Instability of eating disorder diagnoses: prospective study. $\mathrm{Br}$ J Psychiatry 2005, 187:573-578.

3. Bulik CM, Sullivan PF, Fear J, Pickering A: Predictors of the development of bulimia nervosa in women with anorexia nervosa. J Nerv Ment Dis 1997, I 85(I I):704-707.

4. Eddy KT, Keel PK, Dorer DJ, Delinsky SS, Franko DL, Herzog DB: Longitudinal comparison of anorexia nervosa subtypes. Int $J$ Eat Disord 2002, 3 I (2): | 9 I-20I.

5. Strober M, Freeman R, Morrell W: The long-term course of severe anorexia nervosa in adolescents: survival analysis of recovery, relapse, and outcome predictors over $10-15$ years in a prospective study. Int J Eat Disord 1997, 22(4):339-360.

6. Tozzi F, Thornton LM, Klump KL, Fichter MM, Halmi KA, Kaplan AS, Strober M, Woodside DB, Crow S, Mitchell J, Rotondo A, Mauri M, Cassano G, Keel P, Plotnicov KH, Pollice C, Lilenfeld LR, Berrettini WH, Bulik CM, Kaye WH: Symptom fluctuation in eating disorders: correlates of diagnostic crossover. Am J Psychiatry 2005, I 62(4):732-740.

7. Fichter MM, Quadflieg N, Hedlund S: Twelve-year course and outcome predictors of anorexia nervosa. Int J Eat Disord 2006, 39(2):87-100.

8. Deter HC, Herzog W: Anorexia nervosa in a long-term perspective: results of the Heidelberg-Mannheim Study. Psychosom Med 1994, 56(I):20-27.

9. Steinhausen $\mathrm{HC}$ : The outcome of anorexia nervosa in the 20th century. Am J Psychiatry 2002, I 59(8): I284-I 293.

10. Kitagawa N, Asakura S, Kusumi I, Denda K, Koyama T: Temperament and Character of patients with eating disorders: an association between personality and clinical manifestations (in Japanese). Seishin lgaku 2002, 44(4):38I-389.

11. Enns MW, Cox BJ: Perfectionism and depression symptom severity in major depressive disorder. Behav Res Ther 1999. 37(8):783-794.

12. Bydlowski S, Corcos M, Jeammet P, Paterniti S, Berthoz S, Laurier C, Chambry J, Consoli SM: Emotion-processing deficits in eating disorders. Int J Eat Disord 2005, 37(4):32I-329.

13. Nagata T, Oshima J, Wada A, Yamada H, Iketani T, Kiriike N: Temperament and character of Japanese eating disorder patients. Compr Psychiatry 2003, 44(2): I $42-145$.

14. Ruuska J, Kaltiala-Heino R, Rantanen P, Koivisto AM: Psychopathological distress predicts suicidal ideation and self-harm in 
adolescent eating disorder outpatients. Eur Child Adolesc Psychiatry 2005, 14(5):276-28I.

15. Kleifield El, Sunday S, Hurt S, Halmi KA: The effects of depression and treatment on the Tridimensional Personality Questionnaire. Biol Psychiatry 1994, 36(I):68-70.

16. Vervaet M, van Heeringen C, Audenaert K: Personality-related characteristics in restricting versus binging and purging eating disordered patients. Compr Psychiatry 2004, 45(1):37-43.

17. Vervaet M, Audenaert K, van Heeringen C: Cognitive and behavioural characteristics are associated with personality dimensions in patients with eating disorders. Eur Eat Disorders Rev 2003, II(5):363-378.

18. Ando T, Komaki G, Naruo T, Okabe K, Takii M, Kawai K, Konjiki F, Takei M, Oka T, Takeuchi K, Masuda A, Ozaki N, Suematsu H, Denda K, Kurokawa N, Itakura K, Yamaguchi C, Kono M, Suzuki T, Nakai Y, Nishizono-Maher A, Koide M, Murakami K, Nagamine K, Tomita Y, Ookuma K, Tomita K, Tonai E, Ooshima A, Ishikawa T, Ichimaru Y: Possible role of preproghrelin gene polymorphisms in susceptibility to bulimia nervosa. Am J Med Genet B Neuropsychiatr Genet 2006, I4I(8):929-934.

19. Frost RO, Marten P, Lahart C, Rosenblate R: The dimensions of perfectionism. Cognit Ther Res 1990, I4(5):449-468.

20. Tanaka H, Nagata T, Kiriike N, Kawarada Y, Matsunaga H, Yamagami S: Perfectionism in patients with Eating Disorders (in Japanese). Seishin lgaku I999, 4 I (8):847-853.

21. Cloninger CR, Svrakic DM, Przybeck TR: A psychobiological model of temperament and character. Arch Gen Psychiatry 1993, 50( I 2):975-990.

22. Kijima N, Saito R, Takeuchi M, Yoshino A, Ono Y, Kato M, Kitamura $\mathrm{T}$ : Cloninger's seven-factor model of temperament and character and Japanese version of Temperament and Character Inventory (TCI) (in Japanese). Seishinkashindangaku 1996 7(3):379-399.

23. Kojima M, Furukawa TA, Takahashi H, Kawai M, Nagaya T, Tokudome S: Cross-cultural validation of the Beck Depression Inventory-II in Japan. Psychiatry Res 2002, I I 0(3):29I-299.

24. Bulik CM, Devlin B, Bacanu SA, Thornton L, Klump KL, Fichter MM, Halmi KA, Kaplan AS, Strober M, Woodside DB, Bergen AW, Ganjei JK, Crow S, Mitchell J, Rotondo A, Mauri M, Cassano G, Keel P, Berrettini WH, Kaye WH: Significant linkage on chromosome 10p in families with bulimia nervosa. Am J Hum Genet 2003, 72(I):200-207.

25. Ando T, Ichimaru Y, Konjiki F, Shoji M, Komaki G: Variations in the preproghrelin gene correlate with higher body mass index, fat mass, and body dissatisfaction in young Japanese women. Am J Clin Nutr 2007, 86(I):25-32.

26. Humphrey LL: Structural analysis of parent-child relationships in eating disorders. J Abnorm Psychol 1986, 95(4):395-402.

27. Sassaroli S, Ruggiero GM: The role of stress in the association between low self-esteem, perfectionism, and worry, and eating disorders. Int J Eat Disord 2005, 37(2): |35-I4|.

28. van Furth EF, van Strien DC, Martina LM, van Son MJ, Hendrickx JJ, van Engeland $\mathrm{H}$ : Expressed emotion and the prediction of outcome in adolescent eating disorders. Int J Eat Disord 1996 , 20(I): $|9-3|$

29. Bulik CM, Sullivan PF, Fear JL, Pickering A: Outcome of anorexia nervosa: eating attitudes, personality, and parental bonding. Int J Eat Disord 2000, 28(2): 139-147.

30. Fassino S, Abbate-Daga G, Amianto F, Leombruni P, Boggio S, Rovera GG: Temperament and character profile of eating disorders: a controlled study with the Temperament and Character Inventory. Int J Eat Disord 2002, 32(4):4I 2-425.

31. Halvorsen I, Heyerdahl S: Girls with anorexia nervosa as young adults: personality, self-esteem, and life satisfaction. Int J Eat Disord 2006, 39(4):285-293.

32. Spoor STP, Stice E, Bekker MHJ, Van Strien T, Croon MA, Van Heck GL: Relations between dietary restraint, depressive symptoms, and binge eating: a longitudinal study. Int J Eat Disord 2006, 39(8):700-707.

33. Gilbert N, Meyer C: Fear of negative evaluation and the development of eating psychopathology: a longitudinal study among nonclinical women. Int J Eat Disord 2005, 37(4):307-3I 2.

34. Young EA, Clopton JR, Bleckley MK: Perfectionism, low selfesteem, and family factors as predictors of bulimic behavior. Eat Behav 2004, 5(4):273-283.
35. Stice E: Risk and maintenance factors for eating pathology: a meta-analytic review. Psychol Bull 2002, I 28(5):825-848.

36. Tenconi E, Lunardi N, Zanetti T, Santonastaso P, Favaro A: Predictors of binge eating in restrictive anorexia nervosa patients in Italy. J Nerv Ment Dis 2006, 194(9):7 |2-7| 5.

37. Stice E, Hayward C, Cameron RP, Killen JD, Taylor CB: Body-image and eating disturbances predict onset of depression among female adolescents: a longitudinal study. J Abnorm Psychol 2000 , 109(3):438-444.

38. Naito M, Kijima N, Kitamura T: Temperament and Character Inventory $(\mathrm{TCl})$ as predictors of depression among Japanese college students. / Clin Psychol 2000, 56( ( 2): 1579-I 585.

39. Dancyger I, Fornari V, Scionti L, Wisotsky W, Sunday S: Do daughters with eating disorders agree with their parents' perception of family functioning? Compr Psychiatry 2005, 46(2): I35-I39.

40. Halmi KA, Sunday SR, Strober M, Kaplan A, Woodside DB, Fichter M, Treasure J, Berrettini WH, Kaye WH: Perfectionism in anorexia nervosa: variation by clinical subtype, obsessionality, and pathological eating behavior. Am J Psychiatry 2000, I 57(I I): I 799-I805.

4I. Klump KL, Bulik CM, Pollice C, Halmi KA, Fichter MM, Berrettini WH, Devlin B, Strober M, Kaplan A, Woodside DB, Treasure J, Shabbout M, Lilenfeld LR, Plotnicov KH, Kaye WH: Temperament and character in women with anorexia nervosa. J Nerv Ment Dis 2000, 188(9):559-567.

42. Fassino S, Piero A, Gramaglia C, Daga GA, Gandione M, Rovera GG, Bartocci G: Clinical, psychological, and personality correlates of asceticism in anorexia nervosa: from saint anorexia to pathologic perfectionism. Transcult Psychiatry 2006, 43(4):600-6I4.

43. Mulder RT, Joyce PR, Sullivan PF, Bulik CM, Carter FA: The relationship among three models of personality psychopathology: DSM-III-R personality disorder, TCI scores and DSQ defences. Psychol Med 1999, 29(4):943-95I.

44. Svrakic DM, Draganic S, Hill K, Bayon C, Przybeck TR, Cloninger CR: Temperament, character, and personality disorders: etiologic, diagnostic, treatment issues. Acta Psychiatr Scand 2002, 106(3): $189-195$.

45. Grucza RA, Przybeck TR, Spitznagel EL, Cloninger CR: Personality and depressive symptoms: a multi-dimensional analysis. Affect Disord 2003, 74(2): I 23-130.

46. Klump KL, Strober M, Bulik CM, Thornton L, Johnson C, Devlin B, Fichter MM, Halmi KA, Kaplan AS, Woodside DB, Crow S, Mitchell J Rotondo A, Keel PK, Berrettini WH, Plotnicov K, Pollice C, Lilenfeld LR, Kaye WH: Personality characteristics of women before and after recovery from an eating disorder. Psychol Med 2004, 34(8): $|407-14| 8$

47. Vitousek K, Manke F: Personality variables and disorders in anorexia nervosa and bulimia nervosa. J Abnorm Psychol 1994, 103(I):|37-147.

48. Conley J: Longitudinal stability of personality traits: A multitrait-multimethod-multioccasion analysis. J Pers Soc Psychol 1985, 49(5): I 266-1282.

49. Roberts $B$, DelVecchio $W$ : The rank-order consistency of personality traits from childhood to old age: $A$ quantitative review of longitudinal studies. Psychol Bull 2000, I 26(I):3-25.

Publish with Bio Med Central and every scientist can read your work free of charge

"BioMed Central will be the most significant development for disseminating the results of biomedical research in our lifetime. "

Sir Paul Nurse, Cancer Research UK

Your research papers will be:

- available free of charge to the entire biomedical community

- peer reviewed and published immediately upon acceptance

- cited in PubMed and archived on PubMed Centra

- yours - you keep the copyright 